\title{
In-hospital mortality and stroke after surgical aortic valve replacement: A nationwide perspective
}

\author{
Shikhar Agarwal, MD, MPH, ${ }^{a}$ Aatish Garg, MD, ${ }^{b}$ Akhil Parashar, MD, ${ }^{b}$ Lars G. Svensson, MD, PhD, \\ E. Murat Tuzcu, MD, ${ }^{\mathrm{a}}$ Jose L. Navia, MD, ${ }^{\mathrm{c}}$ Stephanie Mick, MD, ${ }^{\mathrm{c}}$ and Samir R. Kapadia, MD ${ }^{\mathrm{a}}$
}

\begin{abstract}
Background: Stroke is a widely recognized complication after aortic valve replacement (AVR), especially among elderly patients. The literature contains substantial variability in reports of the actual incidence of stroke after AVR among high-risk patients. Our objective was to define risk of stroke in patients undergoing surgical AVR, using a large national database.
\end{abstract}

Methods: We used the 2002 to 2011 Nationwide Inpatient Sample database for this analysis. All patients undergoing isolated AVR, or AVR with coronary artery bypass grafting (AVR + CABG), were identified using standard International Classification of Diseases codes. In-hospital mortality and any adverse neurologic event were the primary outcomes of the study.

Results: The incidence of in-hospital mortality was 3.0\% and 5.1\%, respectively, among patients undergoing isolated AVR and AVR + CABG; it was significantly lower in high-volume centers. The incidence of any adverse neurologic event was $2.0 \%$ and $2.9 \%$, respectively, among patients undergoing isolated AVR, and AVR + CABG. We demonstrated a progressive increase in the risk of in-hospital mortality and adverse neurologic events with increasing age. Neurologic events increased with age, from $1.3 \%$ for patients aged $<70$ years, to $3.2 \%$ for those aged $>85$ years, for isolated AVR; and from $2.3 \%$ to $3.6 \%$ for AVR + CABG. The incidence of in-hospital mortality was as high as $5.7 \%$ and $7.4 \%$, respectively, among patients aged $>85$ years undergoing isolated AVR, and AVR + CABG. Similarly, the incidence of any adverse neurologic event was $3.2 \%$ and $3.6 \%$, respectively, among patients aged $>85$ years undergoing isolated AVR, and AVR + CABG. In addition, the risk of adverse neurologic events was significantly higher in the high-risk surgical cohort, compared with the low-risk surgical cohort (odds ratio [95\% confidence interval]; isolated AVR: 2.38 [1.99-2.86]; AVR + CABG: 1.88 [1.57-2.24]).

Conclusions: The incidence of in-hospital mortality and adverse neurologic events was significantly higher among patients with advanced age and elevated surgical risk. (J Thorac Cardiovasc Surg 2015;150:571-8)

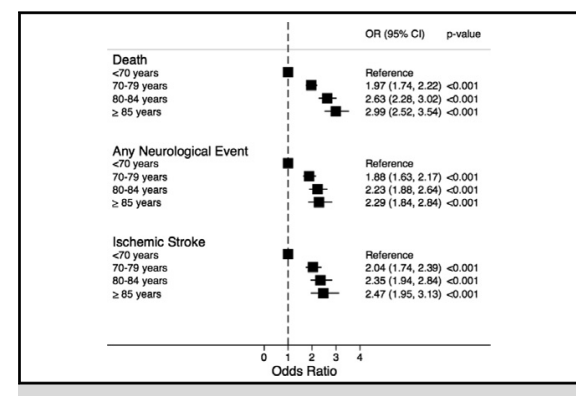

Adjusted comparison of study outcomes among the various age groups for isolated aortic valve replacement.

\section{Central Message}

The incidence of in-hospital death and neurologic events were both higher among patients with advanced age and elevated surgical risk undergoing AVR.

\section{Perspective}

In this large, real-world study of patients undergoing AVR, we demonstrated a progressive increase in hospital death and neurologic events with increasing age. Among patients age $\geq 85$ years undergoing AVR, and AVR + CABG, respectively, the incidence of in-hospital mortality was as high as $5.7 \%$ and $7.4 \%$, and of neurologic events, $3.2 \%$ and $3.6 \%$. High-volume centers had better outcomes compared with low-volume centers.

See Editorial Commentary page 579.

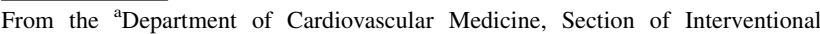
Cardiology, Heart and Vascular Institute, ${ }^{\mathrm{b}}$ Department of Internal Medicine, and ${ }^{\mathrm{c}}$ Department of Thoracic and Cardiovascular Surgery, Heart and Vascular Institute, Cleveland Clinic, Cleveland, Ohio.

Received for publication Feb 19, 2015; revisions received April 21, 2015; accepted for publication May 22, 2015; available ahead of print July 14, 2015.

Address for reprints: Samir R. Kapadia, MD, Sones Cardiac Catheterization Laboratories, Department of Cardiovascular Medicine, J2-3, Heart and Vascular Institute, Cleveland Clinic, 9500 Euclid Ave, Cleveland, OH 44195 (E-mail: kapadis@ccf.org).

$0022-5223 / \$ 36.00$

Copyright (c) 2015 by The American Association for Thoracic Surgery

http://dx.doi.org/10.1016/j.jtcvs.2015.05.068
}

Supplemental material is available online.

With the proportion of elderly people in the population rising rapidly, senile calcific aortic stenosis is one of the most common valvular disorders affecting adults in the United States, ${ }^{1-3}$ accounting for $\geq 92,000$ aortic valve replacements (AVRs) annually. ${ }^{4}$ Surgical AVR traditionally has been regarded as the treatment of choice for patients with severe symptomatic aortic stenosis who do not have a prohibitive risk for heart surgery because of advancing age or other concomitant comorbidities. A significant 


\section{Abbreviations and Acronyms \\ AVR = aortic valve replacement \\ $\mathrm{CABG}=$ coronary artery bypass grafting \\ $\mathrm{CI}=$ confidence interval \\ ICD = International Classification of Diseases \\ NIS = Nationwide Inpatient Sample \\ OR = odds ratio \\ TAVR $=$ transcatheter aortic valve replacement}

proportion of physicians remain reluctant to recommend surgical AVR for patients aged $>80$ years, or those with very high risk for heart surgery. ${ }^{5-7}$

With the advent of transcatheter aortic valve replacement (TAVR), the treatment of severe symptomatic aortic stenosis has been revolutionized, especially for patients who are deemed to be "inoperable" or at "high risk" for traditional surgical AVR. The pivotal PARTNER (Placement of Aortic Transcatheter Valves) trial has conclusively established the noninferiority of TAVR, compared with surgical AVR among high-risk patients with severe symptomatic aortic stenosis. ${ }^{89}$ Despite similar mortality among patients randomized to TAVR or surgical AVR, the prevalence of peri-procedural and long-term adverse neurologic events among patients randomized to TAVR was significantly higher, bringing this procedure under further scrutiny. ${ }^{9}$

The current literature provides heterogeneous rates of adverse complications, including in-hospital mortality and neurologic complications after surgical AVR. This heterogeneity, especially from the clinical trials, has raised the issue of whether the real-life stroke rate after surgical AVR in high-risk patients is different from that in the trial setting. Although age has been perceived to be a major determinant for increased postoperative mortality and adverse neurologic events, a systematic characterization of these event rates among elderly and high-risk patients is currently lacking. To address this issue, we aimed to assess the incidence of in-hospital mortality and adverse neurologic events after surgical AVR (with or without coronary artery bypass grafting $[\mathrm{CABG}]$ ), especially among elderly and high-risk patients, using a large, representative, nationwide sample of hospital discharges.

\section{METHODS \\ Data Source}

Data from 2002 to 2011 were obtained from the Nationwide Inpatient Sample (NIS) database. The NIS is sponsored by the Agency for Healthcare Research and Quality, as a part of the Healthcare Cost and Utilization Projection, and contains discharge-level data from roughly 8 million hospitalizations annually, from approximately 1000 hospitals across the country. This database is designed to represent a $20 \%$ stratified sample of all hospitals in the United States. Criteria used for stratified sampling of hospitals into the NIS include location (rural or urban), teaching status, geographic region, hospital ownership, and patient volume.

The use of the NIS for this study permitted inclusion of all patients undergoing AVR at the included hospitals. The database helps circumvent the limitations of single-center studies, as well as randomized controlled trials, and provides real-world estimates of adverse outcomes after surgery. The true strength of this database is that it provides real-world estimates in a high-risk surgical population. In recent years, many studies have been published using this database, giving it reasonable credibility and validity.

\section{Study Population and Hospitals}

The NIS database provides up to 15 diagnoses and 15 procedures for each hospitalization record for the years 2002 to 2009. The number of diagnoses coded in the database was expanded to 25 for the years 2010 to 2011. All these have been coded using the standard International Classification of Diseases, 9th edition, Clinical Modification (ICD-9 $\mathrm{CM}$ ) codes. In addition, we used the Healthcare Cost and Utilization Projection Clinical Classification Software to identify patient comorbidities and specific procedures. ${ }^{10}$ This software was developed to cluster patient diagnoses and procedures into a manageable number of clinically meaningful categories. ${ }^{10}$

All patients undergoing AVR were identified using the ICD-9 codes 35.21 or 35.22 . Among this cohort, patients undergoing $\mathrm{CABG}$ in addition to AVR were identified using the code 44 within the software. Patients undergoing additional valvular or aortic surgeries were excluded. In addition, patients who underwent AVR for infective endocarditis, and those with end-stage renal disease, were excluded from the study. Additional sensitivity analyses were performed after excluding patients who had cardiogenic shock or acute myocardial infarction, to understand the impact of specific high-risk conditions on the incidence of in-hospital mortality and stroke.

Baseline characteristics available for analysis included age, gender, race, Elixhauser comorbidities defined by the Agency for Healthcare Research and Quality, and other clinically relevant comorbidities (smoking, family history of coronary artery disease, prior myocardial infarction, and dyslipidemia). ${ }^{11,12}$ The NIS database provides 29 Elixhauser comorbidities on each hospital admission, based on standard ICD-9 codes. We used this information to calculate the total number of Elixhauser comorbidities for each admission, and this value was the principal covariate in the multivariate analysis. In addition to these Elixhauser comorbidities, a complete list of ICD-9 codes and Clinical Classification Software codes that were utilized to define the procedures, comorbidities, and outcomes is provided in Table E1.

Hospital characteristics, such as location (rural, urban) and teaching status were included. In addition, we calculated the total number of AVRs performed by each hospital per year. All hospitals performing $\geq 200$ AVRs per year were designated as high-volume centers. Hospitals performing either 50 to 199 AVRs or $<50$ AVRs per year were designated as intermediate-volume and low-volume centers, respectively.

\section{Study Outcomes}

In-hospital mortality and adverse neurologic events were the primary outcomes of our study. Adverse neurologic events were defined as the occurrence of ischemic stroke, transient ischemic attack, subarachnoid hemorrhage, or intracranial hemorrhage during the hospital stay. In addition, we studied the incidence of in-hospital ischemic stroke as a secondary outcome. The respective ICD-9 and software codes for these diagnoses are listed in Table E1.

\section{Statistical Analysis}

Continuous variables are presented as mean $\pm \mathrm{SD}$; categoric variables are presented as proportions. The Student $t$ test was used for comparing 
means between 2 groups. For comparing the means of continuous variables among $\geq 3$ categories, we used 1-way analysis of variance (ANOVA). A $\chi^{2}$ analysis was used to compare proportions among the various categories. Because race was the most common missing variable in the dataset $(21.5 \%)$, we used multiple imputations with ordered logistic regression, accounting for the hospital-based sampling structure of the entire dataset. ${ }^{13}$

Two discrete analyses were performed. The first analysis involved comparison of incidence rates of primary and secondary outcomes, stratified by age. We divided the entire cohort into 4 age groups (in years): $<70 ; 70$ to $79 ; 80$ to 84 ; and $\geq 85$. Multivariable logistic regression analysis was performed with individual outcomes as dependent variables and age category as the primary independent variable. A significant interaction was noted between age category and type of surgery. In addition to age category and type of surgery, additional covariates incorporated into the regression model included gender, congestive heart failure, diabetes, hypertension, smoking, hyperlipidemia, liver disease, chronic lung disease, obesity, peripheral artery disease, prior myocardial infarction, prior cerebrovascular accident, hospital volume, hospital location, and hospital teaching status. Additional sensitivity analyses were performed after excluding patients presenting with cardiogenic shock or acute myocardial infarction, to understand the impact of specific high-risk conditions on the incidence of in-hospital mortality and stroke.

The second analysis was intended to determine the risk of adverse neurologic events and ischemic stroke among patients who were at high risk for mortality after operative intervention. To determine the surgical risk, we constructed a multivariable logistic regression model incorporating age category, gender, total number of Elixhauser comorbidities, and hospital characteristics. Subsequently, predicted probability for inhospital mortality was calculated based on this multivariable regression model. High surgical risk was defined as a predicted probability of inhospital mortality of $>8 \%$. We calculated the incidence rates of any adverse neurologic event and ischemic stroke among the entire surgical cohort after stratifying by surgical risk.

In addition, we performed multivariable regression modeling, with any adverse neurologic event and ischemic stroke as dependent variables. The covariates incorporated into the regression model included gender, congestive heart failure, diabetes, hypertension, smoking, hyperlipidemia, liver disease, chronic lung disease, obesity, peripheral artery disease, prior myocardial infarction, prior cerebrovascular accident, type of surgery, hospital volume, hospital location, and hospital teaching status. A significant interaction was noted between the surgical risk category and the type of surgery, which was accounted for by incorporation of interaction variables into the regression model.

All statistical analyses were performed using the statistical software Stata, version 13.1 (Stata Corporation, College Station, Tex). All statistical tests were 2-tailed.

\section{RESULTS}

During the 10-year period from which data were included (2002-2011), a total of 104,699 admissions occurred, of patients who had AVR during the period of hospitalization. Of these, 57,324 procedures were isolated AVRs; 47,375 were AVRs performed along with CABG $(A V R+C A B G)$. Significant differences are evident, in the demographics as well as clinical characteristics of patients undergoing isolated AVR, compared with those undergoing AVR + CABG (Table 1). In addition, analysis of the characteristics of the hospitals where these procedures were performed indicates that most of these centers were in urban areas $(96.8 \%)$, and were teaching hospitals $(64.8 \%$; Table 1). Significant demographic and clinical differences are evident across age groups among patients undergoing isolated AVR versus AVR + CABG (Tables E2 and E3).

The incidence of in-hospital mortality was $3.0 \%$ and $5.1 \%$, among patients undergoing isolated AVR, and AVR + CABG, respectively $(P<.001)$ (Table 2$)$. In addition, the incidence of any adverse neurologic event was significantly higher among patients undergoing AVR + CABG (2.9\%), compared with those undergoing isolated AVR $(2.0 \%, P<.001)$. Similarly, the incidence of ischemic strokes was significantly higher among patients undergoing AVR + CABG (2.4\%), compared with those undergoing isolated AVR $(1.7 \%, P<.001)$ (Table 2).

\section{Impact of Age on Outcomes After AVR}

Among patients undergoing isolated AVR, a statistically significant increase occurred in the incidence of in-hospital mortality across age groups (Table 3). A statistically significant trend was found, toward an increase in the incidence of any adverse neurologic event, as well as ischemic stroke, across age groups. Among patients undergoing AVR + CABG, a statistically significant increase was found in incidence of in-hospital mortality, any adverse neurologic event, and ischemic stroke across age groups (Table 4).

The adjusted comparison of outcomes among the various age groups for isolated AVR (Figure 1, A) and AVR + CABG (Figure 1, B), derived using multivariable logistic regression analysis, shows that, compared with patients aged $<70$ years, those aged $\geq 85$ years had a significantly higher adjusted risk of in-hospital mortality (OR [95\% CI]: 2.99 [2.52-3.54]), any adverse neurologic event (OR [95\% CI]: 2.29 [1.84-2.84]), and ischemic stroke (OR [95\% CI]: 2.47 [1.95-3.13]). Similarly, compared with patients aged $<70$ years undergoing AVR $+\mathrm{CABG}$, those aged $\geq 85$ years had a significantly higher adjusted risk of in-hospital mortality (OR [95\% CI]: 1.59 [1.36-1.86]), any adverse neurologic event (OR $\left[\begin{array}{lll}95 \% & \mathrm{CI}\end{array}\right]$ : 1.36 [1.11-1.68]), and ischemic stroke (OR [95\% CI]: 1.30 [1.04-1.63]).

\section{Impact of Surgical Risk on Outcomes After AVR}

The multivariable logistic regression analysis that was used to calculate predicted mortality for each patient undergoing AVR shows that the model was most heavily influenced by age, female gender, and the total number of comorbidities present in each patient (Figure E1). On the basis of predicted mortalities determined using this multivariable regression model, the entire cohort was divided into low-risk patients $(\mathrm{n}=95,479)$ and high-risk patients $(n=7337)$. Analysis of the incidence of adverse outcomes among patients undergoing isolated AVR, stratified by surgical risk, shows that in-hospital mortality was $2.8 \%$ in the low-risk category, compared with $6.4 \%$ 
TABLE 1. Baseline characteristics stratified by type of surgery

\begin{tabular}{|c|c|c|c|c|}
\hline Characteristics & All patients & Isolated AVR & AVR + CABG & $P$ value \\
\hline $\mathrm{N}$ & 104,699 & 57,324 & 47,375 & \\
\hline Age (y), mean (SD) & $69.8(12.8)$ & $67.2(14.4)$ & $73.0(9.5)$ & $<.001$ \\
\hline Gender, female & $39,667(37.9)$ & $24,321(42.5)$ & $15,346(32.4)$ & $<.001$ \\
\hline Race & & & & $<.001$ \\
\hline White & $89,030(85.1)$ & $47,875(83.5)$ & $41,155(86.9)$ & \\
\hline Black & $4542(4.3)$ & $2837(5.0)$ & 1705 (3.6) & \\
\hline Other & $11,091(10.6)$ & $6597(11.5)$ & $4494(9.5)$ & \\
\hline \multicolumn{5}{|l|}{ Comorbidities } \\
\hline Diabetes without complications & $23,275(22.5)$ & $11,249(19.9)$ & $12,026(25.8)$ & $<.001$ \\
\hline Diabetes with complications & $3515(3.4)$ & $1563(2.8)$ & $1952(4.2)$ & $<.001$ \\
\hline Hypertension & $64,270(62.2)$ & $34,280(60.7)$ & $29,890(64.1)$ & $<.001$ \\
\hline Smoking & $22,643(21.6)$ & $12,737(22.2)$ & $9906(21.9)$ & $<.001$ \\
\hline Liver disease & $1135(1.1)$ & $740(1.3)$ & $395(0.9)$ & $<.001$ \\
\hline Dyslipidemia & $44,010(42.0)$ & $22,571(39.4)$ & $21,439(45.3)$ & $<.001$ \\
\hline Obesity & $11,782(11.4)$ & $6988(12.3)$ & $4794(10.3)$ & $<.001$ \\
\hline Peripheral artery disease & $12,906(12.5)$ & $6279(11.1)$ & $6627(14.2)$ & $<.001$ \\
\hline Chronic pulmonary disease & $21,122(20.5)$ & $11,243(19.8)$ & $9879(21.2)$ & $<.001$ \\
\hline Prior stroke & $2337(2.2)$ & $1305(2.3)$ & $1032(2.2)$ & $<.3$ \\
\hline Family history of coronary artery disease & $3227(3.1)$ & $1614(2.8)$ & $1613(3.4)$ & $<.001$ \\
\hline Prior myocardial infarction & $5788(5.5)$ & $2293(4.0)$ & $3495(7.4)$ & $<.001$ \\
\hline Cardiogenic shock & $2837(2.7)$ & $1136(2.0)$ & $1701(3.6)$ & $<.001$ \\
\hline Left ventricular dysfunction & $4843(4.6)$ & $2640(4.6)$ & $2203(4.7)$ & .7 \\
\hline Number of Elixhauser comorbidities, mean (SD) & $3.3(1.6)$ & $3.2(1.6)$ & $3.4(1.6)$ & $<.001$ \\
\hline \multicolumn{5}{|l|}{ Hospital characteristics } \\
\hline Volume (/y) & & & & $<.001$ \\
\hline$<50$ & $26,353(25.8)$ & $14,154(24.7)$ & $12,199(25.8)$ & \\
\hline $50-99$ & $28,831(27.5)$ & $15,403(26.9)$ & $13,428(28.3)$ & \\
\hline $100-199$ & $30,185(28.8)$ & $16,312(28.4)$ & $13,873(29.3)$ & \\
\hline$\geq 200$ & $19,330(18.5)$ & $11,455(20.0)$ & 7875 (16.6) & \\
\hline Location & & & & .006 \\
\hline Urban & $100,884(96.8)$ & $55,302(96.9)$ & $45,582(96.6)$ & \\
\hline Rural & $3375(3.2)$ & $1769(3.1)$ & $1606(3.4)$ & \\
\hline Teaching status & & & & $<.001$ \\
\hline Teaching & $67,536(64.8)$ & $37,949(66.5)$ & $29,587(62.7)$ & \\
\hline Nonteaching & $36,723(35.2)$ & $19,122(33.5)$ & $17,601(37.3)$ & \\
\hline
\end{tabular}

Values are n (\%), unless otherwise indicated. $A V R$, Aortic valve replacement; $C A B G$, coronary artery bypass grafting; $S D$, standard deviation.

in the high-risk category $(P<.001)$ (Table E4). Similarly, the incidence of any adverse neurologic event was $1.8 \%$ in the low-risk category, compared with $4.8 \%$ in the high-risk category. In addition, the incidence of ischemic stroke was significantly higher in the high-risk category, compared with the low-risk category $(4.0 \%$ vs $1.5 \%, P<.001)$.

Analysis of the incidence of adverse outcomes among patients undergoing AVR + CABG, stratified by surgical risk, shows that the incidence of in-hospital mortality was $4.7 \%$ in the low-risk category, compared with $9.6 \%$ in the high-risk category $(P<.001)$ (Table E5). Similarly, the incidence of any adverse neurologic event was $2.7 \%$ in the low-risk category, compared with $5.4 \%$ in the high-risk category. The incidence of ischemic stroke was significantly higher in the high-risk category compared with the low-risk category $(4.6 \%$ vs $2.2 \%, P<.001)$.
The comparison of adjusted neurologic outcomes (Figure 2) and ischemic stroke (Figure E2) based on type of surgery and surgical risk showed that patients undergoing isolated AVR had a significantly higher adjusted risk of any adverse neurologic event (OR [95\% CI]: 2.38 [1.99-2.86]) or ischemic stroke (OR [95\% CI]: 2.43 [1.99-2.97]) in the high-risk cohort compared with the low-risk cohort. Similarly, patients undergoing AVR + CABG had a significantly higher adjusted risk of any adverse neurologic event (OR [95\% CI]: 1.88 [1.57-2.24]) or ischemic stroke (OR [95\% CI]: 1.90 [1.57-2.31]) in the high-risk cohort, compared with the low-risk cohort. Among the high-risk cohort, no statistically significant difference was found in the adjusted estimate of any adverse neurologic outcome (OR [95\% CI]: 1.09 [0.88-1.34]), or ischemic stroke (OR [95\% CI]: 1.13 [0.90-1.41]), between the isolated AVR and AVR + CABG cohorts. The impact of 
TABLE 2. Primary outcomes stratified by type of surgery

\begin{tabular}{lrrc}
\hline \multicolumn{1}{c}{ Characteristics } & Isolated AVR & AVR with CABG & $\boldsymbol{P}$ value \\
\hline In-hospital deaths & & & \\
Total cohort & $1739(3.0)$ & $2403(5.1)$ & $<.001$ \\
Urban hospitals & $1697(3.1)$ & $2308(5.1)$ & $<.001$ \\
Rural hospitals & $35(2.0)$ & $85(5.3)$ & $<.001$ \\
Teaching hospitals & $1164(3.1)$ & $1478(5.0)$ & $<.001$ \\
Nonteaching hospitals & $568(3.0)$ & $915(5.2)$ & $<.001$ \\
Hospital volume (/y) & & & \\
$\quad<50$ & $472(3.3)$ & $701(5.8)$ & $<.001$ \\
$\quad 50-99$ & $479(3.1)$ & $685(5.1)$ & $<.001$ \\
100-199 & $484(3.0)$ & $687(5.0)$ & $<.001$ \\
$\quad \geq 200$ & $304(2.7)$ & $330(4.2)$ & $<.001$ \\
Any neurologic events & & & \\
Total cohort & $1162(2.0)$ & $1357(2.9)$ & $<.001$ \\
Urban hospitals & $1129(2.0)$ & $1322(2.9)$ & $<.001$ \\
Rural hospitals & $28(1.6)$ & $30(1.9)$ & .5 \\
Teaching hospitals & $756(2.0)$ & $852(2.9)$ & $<.001$ \\
Nonteaching hospitals & $401(2.1)$ & $500(2.8)$ & $<.001$ \\
Hospital volume (/y) & & & \\
$\quad<50$ & $275(1.9)$ & $352(2.9)$ & $<.001$ \\
50-99 & $348(2.3)$ & $402(3.0)$ & $<.001$ \\
100-199 & $322(2.0)$ & $365(2.6)$ & $<.001$ \\
$\geq 200$ & $217(1.9)$ & $238(3.0)$ & $<.001$ \\
Ischemic stroke & & & \\
Total cohort & $950(1.7)$ & $1147(2.4)$ & $<.001$ \\
Urban hospitals & $922(1.7)$ & $1117(2.5)$ & $<.001$ \\
Rural hospitals & $23(1.3)$ & $25(1.6)$ & .5 \\
Teaching hospitals & $631(1.7)$ & $729(2.5)$ & $<.001$ \\
Nonteaching hospitals & $314(1.6)$ & $413(2.4)$ & $<.001$ \\
Hospital volume (/y) & & & \\
$\quad<50$ & $218(1.5)$ & $294(2.4)$ & $<.001$ \\
50-99 & $276(1.8)$ & $342(2.6)$ & $<.001$ \\
100-199 & $271(1.7)$ & $306(2.2)$ & .001 \\
$\geq 200$ & $185(1.6)$ & $205(2.6)$ & $<.001$ \\
\hline
\end{tabular}

$A V R$, Aortic valve replacement; $C A B G$, coronary artery bypass grafting.

hospital characteristics on outcomes is presented in Appendix 1.

\section{Sensitivity Analyses}

The results of the sensitivity analyses after excluding patients with cardiogenic shock or acute myocardial infarction are shown in Tables E6 and E7. Relatively minor and statistically insignificant differences were present in the incidence of the study endpoints in this cohort, compared with those in the entire cohort presented earlier.

\section{DISCUSSION}

The current study is one of the largest to meticulously characterize the incidence rates of in-hospital mortality and adverse neurologic events among patients undergoing surgical AVR, especially elderly and high-risk patients. The incidence of in-hospital mortality was $3.0 \%$ and $5.1 \%$, respectively, among patients undergoing isolated AVR, and AVR + CABG. The incidence of any adverse
TABLE 3. Outcomes among patients undergoing isolated AVR, stratified by age

\begin{tabular}{|c|c|c|c|c|c|}
\hline \multirow[b]{2}{*}{ Characteristics } & \multicolumn{4}{|c|}{ Age (y) } & \multirow{2}{*}{$\begin{array}{c}P \\
\text { value }\end{array}$} \\
\hline & $<70$ & 70-79 & $80-84$ & $\geq \mathbf{8 5}$ & \\
\hline \multicolumn{6}{|l|}{ In-hospital deaths } \\
\hline Total cohort & $529(1.9)$ & $626(3.5)$ & $379(4.9)$ & $205(5.7)$ & $<.001$ \\
\hline Urban hospitals & $516(1.9)$ & $610(3.5)$ & $369(4.9)$ & $202(5.8)$ & $<.001$ \\
\hline Rural hospitals & $10(1.2)$ & $13(2.3)$ & $9(3.8)$ & $3(2.9)$ & .051 \\
\hline Teaching hospitals & 363 (1.9) & $418(3.7)$ & $234(4.6)$ & $149(6.0)$ & $<.001$ \\
\hline Nonteaching hospitals & $163(1.8)$ & $205(3.2)$ & $144(5.6)$ & $56(5.1)$ & $<.001$ \\
\hline \multicolumn{6}{|l|}{ Hospital volume (/y) } \\
\hline$<50$ & $171(2.4)$ & $166(3.7)$ & $91(5.3)$ & $44(6.7)$ & $<.001$ \\
\hline $50-99$ & 144 (1.9) & $171(3.5)$ & $121(5.8)$ & $43(5.1)$ & $<.001$ \\
\hline $100-199$ & $134(1.7)$ & $181(3.6)$ & $10(4.6)$ & $69(6.6)$ & $<.001$ \\
\hline$\geq 200$ & $80(1.5)$ & $108(3.1)$ & $67(3.8)$ & $49(4.7)$ & $<.001$ \\
\hline \multicolumn{6}{|l|}{ Any neurologic event } \\
\hline Total cohort & $369(1.3)$ & $442(2.5)$ & $234(3.0)$ & $117(3.2)$ & $<.001$ \\
\hline Urban hospitals & $359(1.3)$ & $430(2.5)$ & $224(3.0)$ & $116(3.3)$ & $<.001$ \\
\hline Rural hospitals & $8(0.9)$ & $10(1.8)$ & $9(3.8)$ & $1(1.0)$ & .02 \\
\hline Teaching hospitals & $259(1.4)$ & $272(2.4)$ & $146(2.9)$ & $79(3.2)$ & $<.001$ \\
\hline Nonteaching hospitals & $108(1.2)$ & $168(2.6)$ & $87(3.4)$ & $38(3.4)$ & $<.001$ \\
\hline \multicolumn{6}{|l|}{ Hospital volume (/y) } \\
\hline$<50$ & $86(1.2)$ & $117(2.6)$ & $47(2.7)$ & $25(3.8)$ & $<.001$ \\
\hline $50-99$ & $115(1.5)$ & $133(2.7)$ & $69(3.3)$ & $31(3.6)$ & $<.001$ \\
\hline $100-199$ & $104(1.3)$ & $115(2.3)$ & $64(2.9)$ & $39(3.7)$ & $<.001$ \\
\hline$\geq 200$ & $64(1.2)$ & $77(2.2)$ & $54(3.1)$ & $22(2.1)$ & $<.001$ \\
\hline \multicolumn{6}{|l|}{ Ischemic stroke } \\
\hline Total cohort & $286(1.0)$ & $373(2.1)$ & $192(2.5)$ & $99(2.7)$ & $<.001$ \\
\hline Urban hospitals & $278(1.0)$ & $362(2.1)$ & $183(2.4)$ & $99(2.8)$ & $<.001$ \\
\hline Rural hospitals & $6(0.7)$ & $9(1.6)$ & $8(3.4)$ & 0 & .007 \\
\hline Teaching hospitals & $206(1.1)$ & $234(2.0)$ & $122(2.4)$ & $69(2.8)$ & $<.001$ \\
\hline Nonteaching hospitals & $78(0.9)$ & $137(2.1)$ & $69(2.7)$ & $30(2.7)$ & $<.001$ \\
\hline \multicolumn{6}{|l|}{ Hospital volume (/y) } \\
\hline$<50$ & $60(0.8)$ & $103(2.3)$ & $35(2.0)$ & $20(3.0)$ & $<.001$ \\
\hline $50-99$ & $85(1.1)$ & $102(2.1)$ & $62(3.0)$ & $27(3.2)$ & $<.001$ \\
\hline $100-199$ & $87(1.1)$ & $101(2.0)$ & $50(2.3)$ & $33(3.1)$ & $<.001$ \\
\hline$\geq 200$ & $54(1.0)$ & $67(1.9)$ & $45(2.6)$ & $20(1.8)$ & $<.001$ \\
\hline
\end{tabular}

neurologic event was $2.0 \%$ and $2.9 \%$, respectively, among patients undergoing isolated AVR, and AVR + CABG. We demonstrated a progressive increase in the risk of in-hospital mortality and adverse neurologic events with increasing age. Among patients aged $\geq 85$ years, the incidence of in-hospital mortality was as high as $5.7 \%$ and $7.4 \%$, respectively, for those undergoing isolated AVR, and AVR + CABG; the incidence of any adverse neurologic event was $3.2 \%$ and $3.6 \%$, respectively. High-volume centers demonstrated better outcomes, compared with low-volume centers. Furthermore, outcomes in rural centers seemed to be significantly better than those in urban centers, likely secondary to referral bias and possibly a lower-risk population served by the rural hospitals.

In addition to characterization of the incidence rate of in-hospital mortality and adverse neurologic events, we 
TABLE 4. Outcomes among patients undergoing AVR + CABG, stratified by age

\begin{tabular}{|c|c|c|c|c|c|}
\hline \multirow[b]{2}{*}{ Characteristics } & \multicolumn{4}{|c|}{ Age (y) } & \multirow{2}{*}{$\begin{array}{c}P \\
\text { value }\end{array}$} \\
\hline & $<70$ & 70-79 & $80-84$ & $\geq 85$ & \\
\hline \multicolumn{6}{|l|}{ In-hospital deaths } \\
\hline Total cohort & $580(3.9)$ & $980(5.0)$ & $568(6.4)$ & $275(7.4)$ & $<.001$ \\
\hline Urban hospitals & $556(3.9)$ & $942(5.0)$ & $547(6.4)$ & $263(7.3)$ & $<.001$ \\
\hline Rural hospitals & $20(4.0)$ & $35(5.0)$ & $19(6.2)$ & $11(11.2)$ & .03 \\
\hline Teaching hospitals & $353(3.7)$ & $600(5.0)$ & $336(6.1)$ & $189(7.8)$ & $<.001$ \\
\hline Nonteaching hospitals & $223(4.2)$ & $377(5.0)$ & $230(6.8)$ & $85(6.6)$ & $<.001$ \\
\hline \multicolumn{6}{|l|}{ Hospital volume (/y) } \\
\hline$<50$ & $181(4.4)$ & $284(5.7)$ & $161(7.4)$ & $75(9.2)$ & $<.001$ \\
\hline $50-99$ & $165(4.0)$ & $285(5.0)$ & $151(5.9)$ & $84(8.2)$ & $<.001$ \\
\hline 100-199 & $166(3.9)$ & $275(4.7)$ & $178(6.8)$ & $68(6.1)$ & $<.001$ \\
\hline$\geq 200$ & $68(2.9)$ & $136(4.3)$ & $78(4.9)$ & $48(6.3)$ & $<.001$ \\
\hline \multicolumn{6}{|l|}{ Any neurologic event } \\
\hline Total cohort & $344(2.3)$ & $568(2.9)$ & $311(3.5)$ & 134 (3.6) & $<.001$ \\
\hline Urban hospitals & $334(2.3)$ & $558(2.9)$ & $302(3.5)$ & $128(3.5)$ & $<.001$ \\
\hline Rural hospitals & $6(1.2)$ & $9(1.3)$ & $9(2.9)$ & $6(6.1)$ & .003 \\
\hline Teaching hospitals & $233(2.5)$ & $336(2.8)$ & $194(3.5)$ & $89(3.7)$ & $<.001$ \\
\hline Nonteaching hospitals & $107(2.0)$ & $231(3.0)$ & $117(3.5)$ & $45(3.5)$ & $<.001$ \\
\hline \multicolumn{6}{|l|}{ Hospital volume (/y) } \\
\hline$<50$ & $93(2.2)$ & $161(3.2)$ & $68(3.1)$ & $30(3.7)$ & .02 \\
\hline $50-99$ & $92(2.2)$ & $172(3.0)$ & $104(4.1)$ & $34(3.3)$ & $<.001$ \\
\hline $100-199$ & $91(2.1)$ & $148(2.5)$ & $88(3.4)$ & $38(3.4)$ & .006 \\
\hline$\geq 200$ & $68(2.9)$ & $87(2.7)$ & $51(3.2)$ & $32(4.2)$ & .18 \\
\hline \multicolumn{6}{|l|}{ Ischemic stroke } \\
\hline Total cohort & $299(2.0)$ & $470(2.4)$ & $264(3.0)$ & $114(3.1)$ & $<.001$ \\
\hline Urban hospitals & $289(2.0)$ & $461(2.4)$ & $257(3.0)$ & $110(3.0)$ & $<.001$ \\
\hline Rural hospitals & $6(1.2)$ & $8(1.2)$ & $7(2.3)$ & $4(4.1)$ & .1 \\
\hline Teaching hospitals & $202(2.1)$ & $284(2.4)$ & $166(3.0)$ & $77(3.2)$ & .001 \\
\hline Nonteaching hospitals & $93(1.7)$ & $185(2.4)$ & $98(2.9)$ & $37(2.9)$ & .002 \\
\hline \multicolumn{6}{|l|}{ Hospital volume (/y) } \\
\hline$<50$ & $79(1.9)$ & $132(2.6)$ & $59(2.7)$ & $24(2.9)$ & .07 \\
\hline $50-99$ & $83(2.0)$ & $144(2.5)$ & $87(3.4)$ & $28(2.7)$ & .005 \\
\hline $100-199$ & $77(1.8)$ & $120(2.1)$ & $76(2.9)$ & $33(2.9)$ & .006 \\
\hline$\geq 200$ & $60(2.6)$ & $74(2.3)$ & $2(2.6)$ & $29(3.8)$ & .14 \\
\hline
\end{tabular}

have attempted to characterize these event rates, among patients undergoing AVR, on the basis of predicted surgical risk. Although calculating traditional risk scores such as the Society of Thoracic Surgeons or the EuroSCORE (European System for Cardiac Operative Risk Evaluation) on this discharge-level database was not possible, we were able to calculate predicted mortality on all patients, based on age, gender, concomitant comorbidities, and important hospital characteristics available in the database. We demonstrated a significantly higher risk of adverse neurologic events among the high-risk cohort, compared with the low-risk cohort. Among patients undergoing isolated AVR, the incidence of any adverse neurologic event was $1.8 \%$ and $4.8 \%$ in the low-risk and high-risk cohorts, respectively. Similarly, among patients undergoing AVR + CABG, the incidence of any adverse neurologic event was $2.7 \%$ and $5.4 \%$, respectively, in the low-risk and high-risk cohorts.

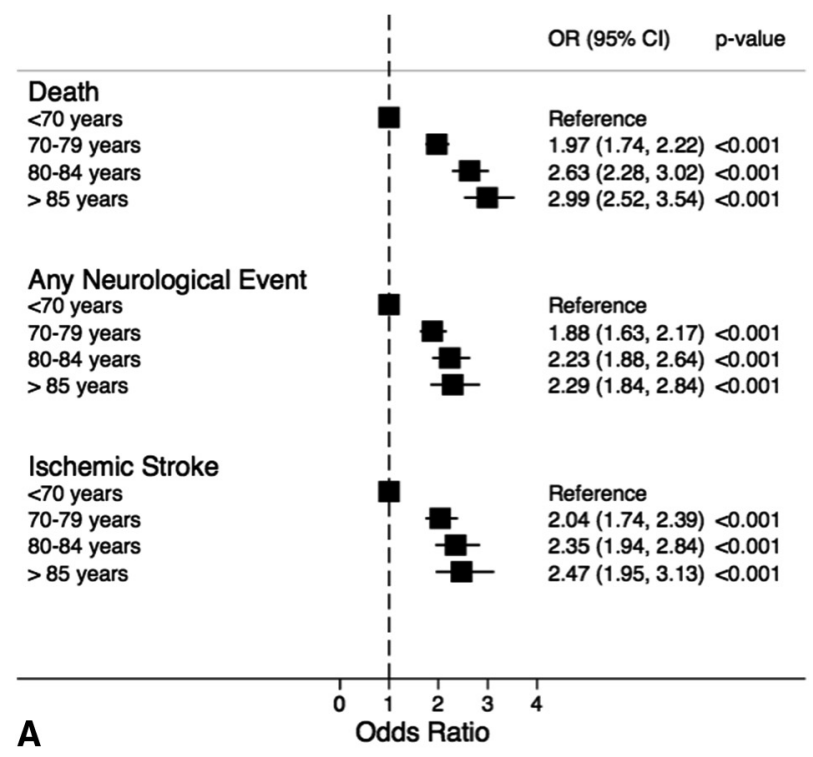

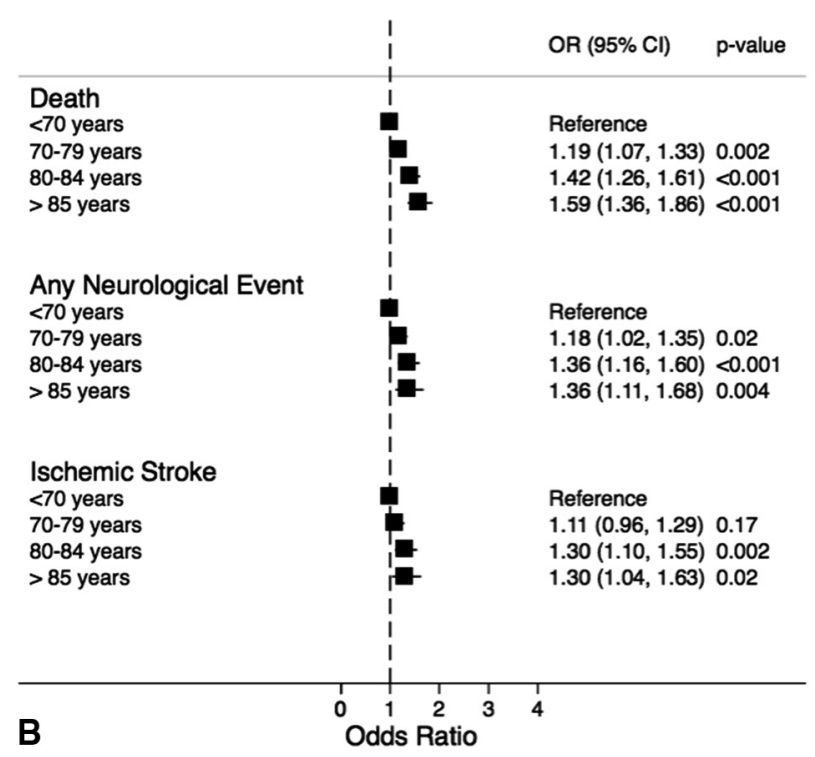

FIGURE 1. This figure demonstrates the adjusted comparison of study outcomes among the various age groups for (A) isolated AVR and (B) $\mathrm{AVR}+\mathrm{CABG}$, derived using multivariable logistic regression analysis. Multivariable logistic regression analysis was performed with individual outcomes as dependent variables and age category as the primary independent variable. A significant interaction was noted between age category and type of surgery. Additional covariates incorporated into the regression model included: gender, congestive heart failure, diabetes, hypertension, smoking, hyperlipidemia, liver disease, chronic lung disease, obesity, peripheral artery disease, prior myocardial infarction, prior cerebrovascular accident, hospital volume, hospital location, and hospital teaching status. $O R$, Odds ratio; $C I$, confidence interval.

The past decade has witnessed a major improvement in the arena of management of severe symptomatic aortic stenosis. Aside from the new option of TAVR, the results of surgical AVR have shown consistent improvement. The information from the Society of Thoracic Surgeons 


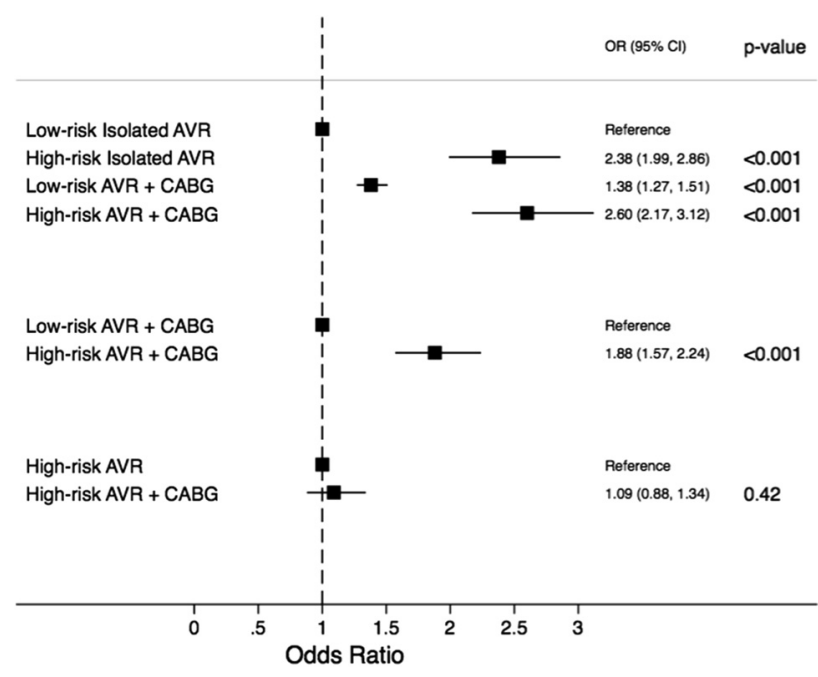

FIGURE 2. Adjusted OR of any adverse neurologic event among various categories formed on the basis of type of surgery (isolated AVR vs $\mathrm{AVR}+\mathrm{CABG}$ ) and surgical risk (high vs low). Results are derived from multivariable logistic regression analysis with any neurologic event as the outcome variable. Besides type of surgery, the other covariates incorporated into the regression model included: age, gender, race, diabetes, hypertension, hyperlipidemia, smoking history, family history of coronary artery disease, liver disease, peripheral artery disease, obesity, Elixhauser comorbidity score, prior myocardial infarction, prior stroke, predicted mortality group (high-risk vs low-risk), hospital volume, teaching hospital status, and hospital location. A significant interaction was found between type of surgery and predicted mortality group, which was accounted for in the regression model. The figure demonstrates comparative ORs among several surgical groups on the basis of predicted mortality and type of surgery. Other significant variables that were independently predictive of any neurologic event were (OR $[95 \% \mathrm{CI}]$ ); age 70 to 79 years: $1.44(1.30-1.59)$; age 80 to 84 years: 1.50 (1.32-1.69); age $\geq 85$ years: 1.44 (1.23-1.69); heart failure: 2.41 (1.98-2.93); diabetes with complications: 1.22 (1.01-1.49); peripheral artery disease: 1.15 (1.02-1.29); prior cerebrovascular accident: 1.29 (1.01-1.66); urban hospital location: 1.37 (1.04-1.77). OR, Odds ratio; $C I$, confidence interval; $A V R$, aortic valve replacement; $C A B G$, coronary artery bypass grafting.

database showed that the operative mortality after isolated AVR has declined ${ }^{14}$ from $3.4 \%$ in 2002 to $2.6 \%$ in 2011. Similarly, we have documented a decline of mortality to consistently $<0.7 \%$ for the past 3 years at our institution. ${ }^{15}$

Adverse neurologic events including ischemic strokes represent a major comorbidity after surgical AVR or TAVR. The Society of Thoracic Surgeons registry reported $^{16}$ that the risk of stroke after isolated surgical AVR between 2002 and 2006 was $1.5 \%$. Similar to the improvement in mortality, the risk of in-hospital stroke has decreased, ${ }^{17}$ from $1.7 \%$ in 1996 to $1.3 \%$ in 2006 . Despite this low overall risk of strokes, the registry has developed risk-prediction models that help calculate the risk of adverse postoperative events such as mortality and stroke after AVR. These scores have been used to risk stratify patients who are candidates for heart surgery, as well as counsel them about the anticipated risk after surgery. The scores predict a $>3$-fold increase in the risk of mortality and cerebrovascular events in a patient aged 80 years, compared with a patient aged 50 years undergoing isolated AVR. $^{16}$

We have seen rapid advances in the use of TAVR technology for treatment of severe symptomatic aortic stenosis in the past few years. Although randomized controlled trials have established that the efficacy of TAVR is similar to that of surgical AVR in terms of mortality, concern has been raised about a higher incidence of stroke after TAVR, compared with surgical AVR. ${ }^{9}$ This concern is based on the stroke rate, which is $4.7 \%$ for transfemoral TAVR in the PARTNER trial, versus $2.4 \%$ for surgical AVR. ${ }^{9,18}$

Several analyses have tried to identify the reasons for this discrepancy, as well as accurately quantify the risk of stroke after surgical AVR and TAVR. ${ }^{18,19}$ The instantaneous risk of stroke after TAVR or surgical AVR demonstrates early peaking, with a high-hazard phase in the first postoperative week, followed by a constant lower-hazard phase throughout the duration of follow-up. This temporal pattern is very similar to that seen for neurologic events after CABG. $^{20}$

The TAVR trials looked for and adjudicated neurologic events differently from the NIS. The neurologic events in the PARTNER trial were adjudicated retrospectively by the Clinical Events Committee, and those in the CoreValve trial were adjudicated prospectively using neurologic consultations and imaging, whenever necessary. The suggestion has been made that the high-risk patients that were randomized to the surgical AVR arms, in the PARTNER as well as the US CoreValve trials, carried a significantly higher risk compared with those who form a part of the traditional registries such as the Society of Thoracic Surgeons registry., 16,21 Our study has attempted to characterize the incidence, as well as the risk of, stroke after surgical AVR, among patients that may be at high risk by virtue of age or multiple medical comorbidities.

\section{Limitations}

Our study has several limitations. First, the NIS is an administrative database, which can be subject to errors in coding of diseases or procedures. Given that the unit of analysis in the NIS database is "unique admission" rather than "unique patient," a single patient could have been represented more than once, as in the case of a repeat admission to the hospital for reoperation. Additionally, owing to the administrative nature of the database, characteristics such as reoperation or cardiopulmonary bypass times could not be determined, and these may be important factors in adverse neurologic events. 
Second, this study is retrospective and observational, meaning it is subject to the standard biases of observational studies, such as selection bias. However, these limitations may be partially compensated for by the large size of the NIS database and the uniform representation of all regions of the United States. A further limitation is that the occurrence of adverse neurologic events and ischemic strokes was not formally adjudicated by a clinical event committee, because of the study design. In addition, death and stroke were measured as events only if they occurred during the index hospitalization, whereas surgical guidelines would capture events out to 30 days, even if the patient had been discharged. Therefore, we speculate that a formal adjudication process would likely identify events that were not reported in the NIS database; thus, the incidence of deaths and strokes after surgical AVR may be underestimated in our study.

\section{CONCLUSIONS}

A progressive increase occurred in the risk of in-hospital mortality and adverse neurologic events with increasing age. The incidence of in-hospital mortality was as high as $5.7 \%$ and $7.4 \%$, respectively, among patients aged $\geq 85$ years undergoing isolated AVR and AVR + CABG; it was higher in low-volume centers compared with high-volume centers. Similarly, the incidence of any adverse neurologic event was $3.2 \%$ and $3.6 \%$, respectively, among patients aged $\geq 85$ years undergoing isolated AVR, and AVR + CABG. In addition, the risk of adverse neurologic events was significantly higher in the high-risk surgical cohort, compared with the low-risk surgical cohort. The incidence of adverse neurologic events was as high as $4.8 \%$ and $5.4 \%$, respectively, among high-risk patients undergoing isolated AVR, and AVR + CABG.

\section{Conflict of Interest Statement}

Authors have nothing to disclose with regard to commercial support.

\section{References}

1. Nkomo VT, Gardin JM, Skelton TN, Gottdiener JS, Scott CG, EnriquezSarano M. Burden of valvular heart diseases: a population-based study. Lancet. 2006;368:1005-11.

2. Ross J Jr, Braunwald E. Aortic stenosis. Circulation. 1968;38(1 Suppl):61-7.

3. Turina J, Hess O, Sepulcri F, Krayenbuehl HP. Spontaneous course of aortic valve disease. Eur Heart J. 1987;8:471-83.
4. Svensson LG, Adams DH, Bonow RO, Kouchoukos NT, Miller DC, O'Gara PT, et al. Aortic valve and ascending aorta guidelines for management and quality measures. Ann Thorac Surg. 2013;95(6 Suppl):S1-66.

5. Bouma BJ, van Den Brink RB, van Der Meulen JH, Verheul HA, Cheriex EC, Hamer HP, et al. To operate or not on elderly patients with aortic stenosis: the decision and its consequences. Heart. 1999;82:143-8.

6. Bramstedt KA. Aortic valve replacement in the elderly: frequently indicated yet frequently denied. Gerontology. 2003;49:46-9.

7. Iung B, Cachier A, Baron G, Messika-Zeitoun D, Delahaye F, Tornos P, et al. Decision-making in elderly patients with severe aortic stenosis: Why are so many denied surgery? Eur Heart J. 2005;26:2714-20.

8. Leon MB, Smith CR, Mack M, Miller DC, Moses JW, Svensson LG, et al. Transcatheter aortic-valve implantation for aortic stenosis in patients who cannot undergo surgery. New Engl J Med. 2010;363:1597-607.

9. Smith CR, Leon MB, Mack MJ, Miller DC, Moses JW, Svensson LG, et al. Transcatheter versus surgical aortic-valve replacement in high-risk patients. New Engl J Med. 2011;364:2187-98.

10. US Agency for Healthcare Research and Quality: Clinical Classifications Software (CCS), 2014. Available at: http://www.hcup-us.ahrq.gov/toolssoftware/ ccs/ccs.jsp. Accessed February 12, 2014.

11. Elixhauser A, Steiner C, Harris DR, Coffey RM. Comorbidity measures for use with administrative data. Med Care. 1998;36:8-27.

12. Agency for Healthcare Research and Quality: Healthcare Cost and Utilization Project: Comorbidity Software, Version 3.7. Available at: http://www.hcup-us. ahrq.gov/toolssoftware/comorbidity/comorbidity.jsp. Accessed February 14, 2014.

13. Qi L, Wang YF, He Y. A comparison of multiple imputation and fully augmented weighted estimators for Cox regression with missing covariates. Stat Med. 2010; 29:2592-604.

14. Thourani VH, Ailawadi G, Szeto WY, Dewey TM, Guyton RA, Mack MJ, et al. Outcomes of surgical aortic valve replacement in high-risk patients: a multi-institutional study. Ann Thorac Surg. 2011;91:49-55; discussion 56.

15. Svensson LG. Aortic valve replacement: options, improvements, and costs. Cleveland Clin J Med. 2013;80:253-4.

16. O'Brien SM, Shahian DM, Filardo G, Ferraris VA, Haan CK, Rich JB, et al. The Society of Thoracic Surgeons 2008 cardiac surgery risk models: part 2-isolated valve surgery. Ann Thorac Surg. 2009;88(1 Suppl):S23-42.

17. Brown JM, O'Brien SM, Wu C, Sikora JA, Griffith BP, Gammie JS. Isolated aortic valve replacement in North America comprising 108,687 patients in 10 years: changes in risks, valve types, and outcomes in the Society of Thoracic Surgeons National Database. J Thorac Cardiovasc Surg. 2009;137: 82-90.

18. Miller DC, Blackstone EH, Mack MJ, Svensson LG, Kodali SK, Kapadia S, et al. Transcatheter (TAVR) versus surgical (AVR) aortic valve replacement: occurrence, hazard, risk factors, and consequences of neurologic events in the PARTNER trial. J Thorac Cardiovasc Surg. 2012;143:832-43.e13.

19. Athappan G, Gajulapalli RD, Sengodan P, Bhardwaj A, Ellis SG, Svensson L, et al. Influence of TAVR strategy and valve design on stroke after transcatheter aortic valve replacement - a meta-analysis and systematic review of literature. J Am Coll Cardiol. 2014;63:2101-10.

20. Tarakji KG, Sabik JF III, Bhudia SK, Batizy LH, Blackstone EH. Temporal onset, risk factors, and outcomes associated with stroke after coronary artery bypass grafting. JAMA. 2011;305:381-90.

21. Adams DH, Popma JJ, Reardon MJ, Yakubov SJ, Coselli JS, Deeb GM, et al. Transcatheter aortic-valve replacement with a self-expanding prosthesis. New Engl J Med. 2014;370:1790-8.

Key Words: aortic valve replacement, stroke, mortality 


\section{APPENDIX 1. IMPACT OF HOSPITAL CHARACTERISTICS ON OUTCOMES}

Several hospital characteristics had a significant impact on the outcomes after AVR in this study cohort. Most procedures were performed in high-volume centers located in urban areas. Most of the hospitals were teaching hospitals. A significant reduction occurred in the incidence of in-hospital mortality as the volume of procedures performed at that hospital increased. The incidence of in-hospital mortality among patients undergoing isolated AVR was $3.3 \%, 3.1 \%, 3.0 \%$, and $2.7 \%$ at hospitals with $<50$ cases/year, 50-99 cases/year, 100-199 cases/year, and $\geq 200$ cases/year, respectively $(P=.01)$ (Table 2). Similarly, the incidence of in-hospital mortality among patients undergoing AVR + CABG was 5.8\%, 5.1\%, $5.0 \%$, and $4.2 \%$ at these hospitals, respectively $(P<.001)$.

We did not find any significant differences in the incidence of any adverse neurologic event or ischemic stroke among the hospitals stratified by procedural volume. In addition, no significant impact was found of teaching status on in-hospital mortality or adverse neurologic event or ischemic stroke incidence among patients undergoing isolated AVR, or AVR + CABG. Furthermore, the incidence of in-hospital mortality was significantly higher among the isolated AVRs performed in urban locations $(3.1 \%)$, compared with those performed in rural locations $(2.0 \%, P=.008)$. Among the AVR + CABG cohort, the incidence of any adverse neurologic event and ischemic stroke was significantly higher at the urban centers compared with the rural centers.

On adjusted analysis, a statistically significant trend was found toward lower in-hospital mortality with increasing hospital volume $(P$ for trend $=.002)$. Compared with the low-volume centers, the risk of in-hospital mortality after AVR was significantly lower in the high-volume centers (OR [95\% CI]: 0.75 [0.69-0.82]). No impact was found of urban location (OR [95\% CI]: 1.08 [0.93-1.26]) or teaching status (OR [95\% CI]: 1.05 [0.99-1.11]) on the odds or in-hospital mortality after AVR. Although hospital volume had no significant impact on any adverse neurologic event, or ischemic stroke, hospital location did have a considerable impact on these outcomes. On multivariable logistic regression analysis, a significantly higher risk was found of any adverse neurologic event (OR $[95 \% \mathrm{CI}]$ : $1.36[1.04-1.77])$, and ischemic stroke (OR [95\% CI]: 1.38 [1.01-1.81]) among patients undergoing AVR at an urban hospital, compared with those undergoing AVR at a rural hospital. 


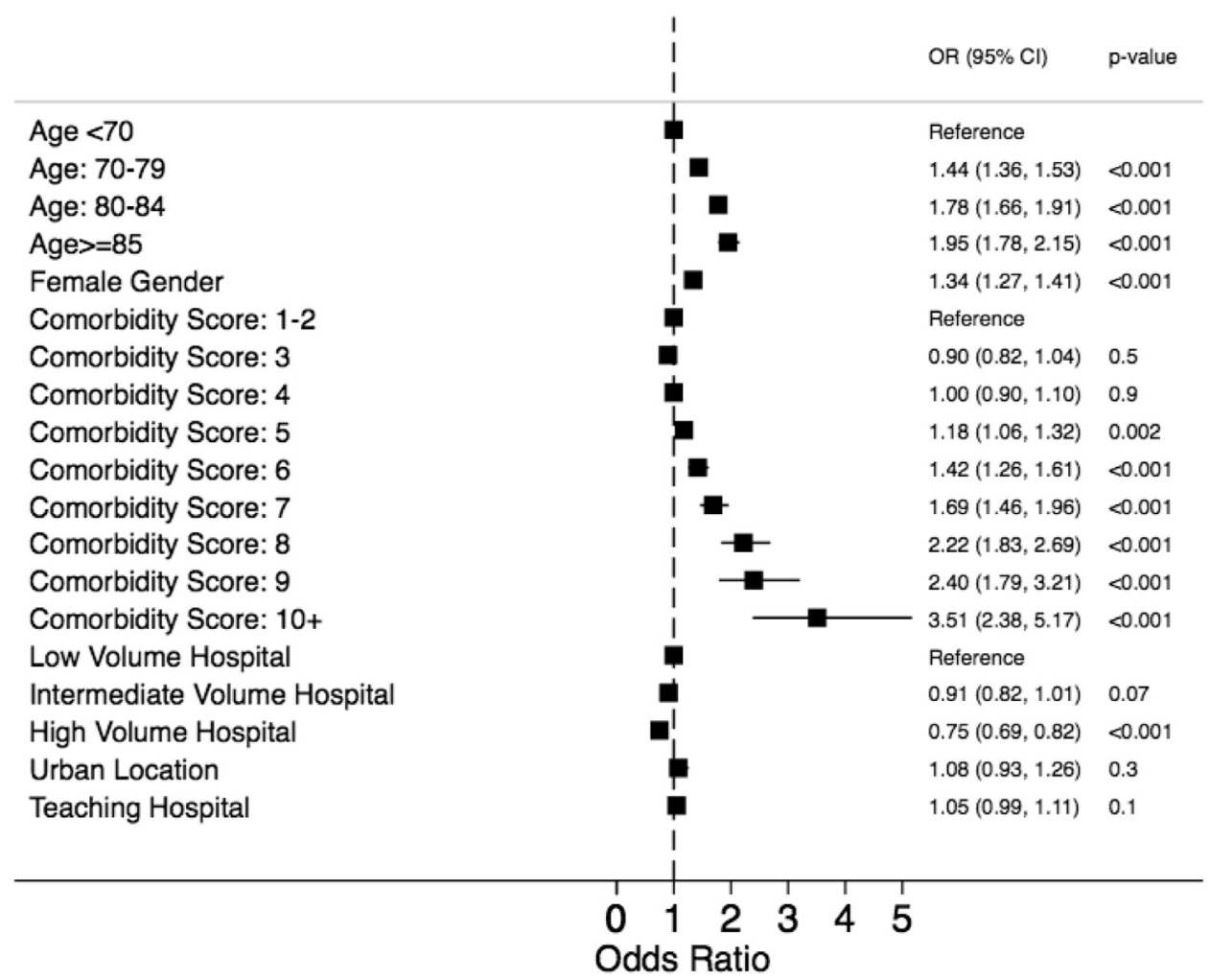

FIGURE E1. This figure demonstrates the multivariable logistic regression analysis used to calculate predicted mortality for each patient undergoing aortic valve replacement. In-hospital mortality was the outcome variable in this multivariable regression model. The independent variables included age group, gender, and Elixhauser comorbidity score, along with hospital characteristics such as volume, location, and teaching status. Low-volume hospitals are those with $<50$ cases per year, intermediate-volume hospitals are those with 50 to 199 cases per year, and high-volume hospitals are those with $\geq 200$ cases per year. $O R$, Odds ratio; $C I$, confidence interval. 


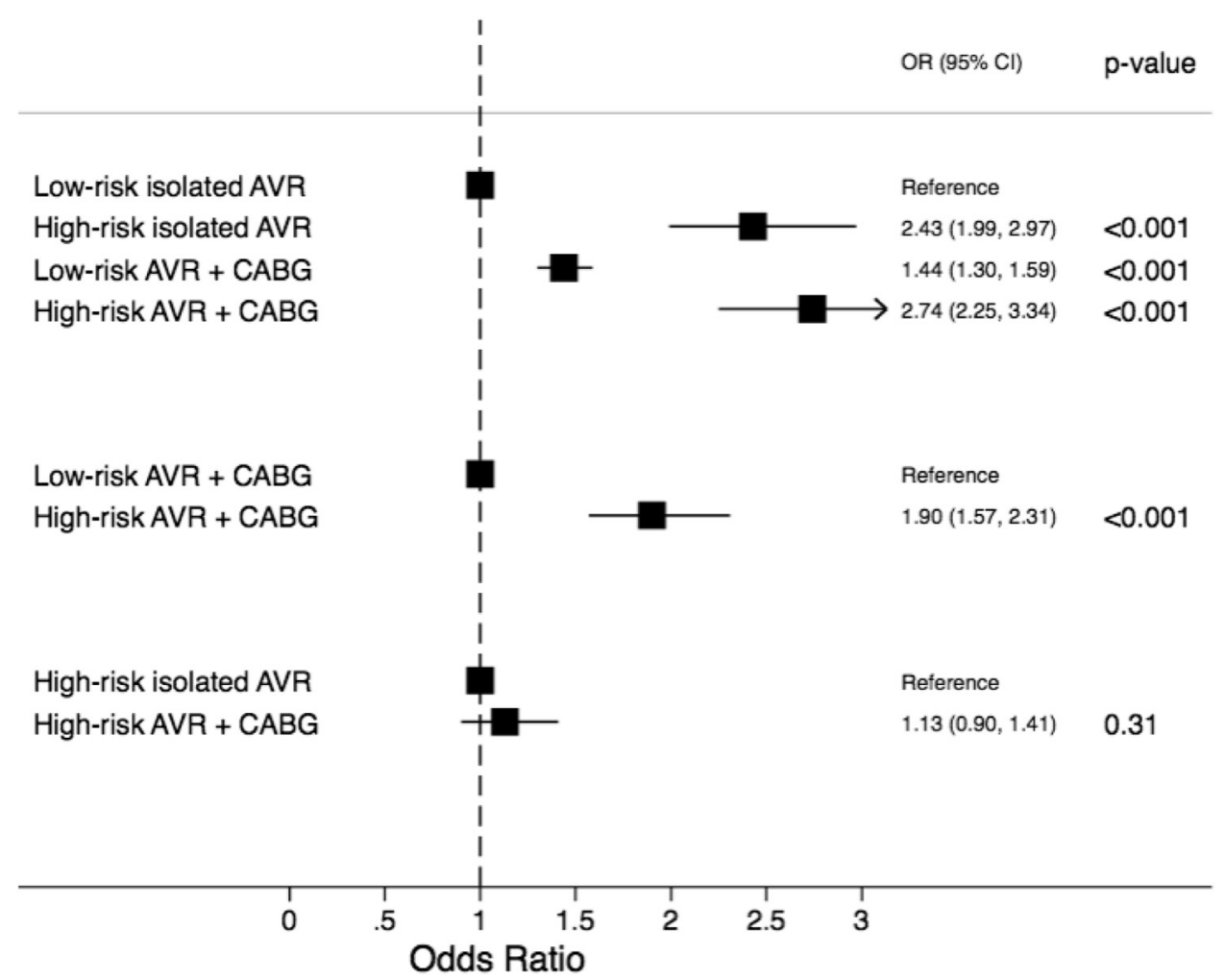

FIGURE E2. Adjusted OR of ischemic stroke among various categories based on type of surgery (isolated AVR vs AVR + CABG), and surgical risk (high vs low). Results are derived from multivariable logistic regression analysis with ischemic stroke as the outcome variable. Besides type of surgery, the other covariates incorporated into the regression model included: age, gender, race, diabetes, hypertension, hyperlipidemia, smoking history, family history of coronary artery disease, liver disease, peripheral artery disease, obesity, Elixhauser comorbidity score, prior myocardial infarction, prior stroke, predicted mortality group (high-risk vs low-risk), hospital volume, teaching hospital status, and hospital location. A significant interaction was found between the type of surgery and the predicted mortality group, which was accounted for in the regression model. The figure demonstrates comparative ORs among several surgical groups on the basis of predicted mortality and type of surgery. Other significant variables that were independently predictive of ischemic stroke were (OR [95\% CI]): age 70-79 years: 1.44 (1.29-1.62); age 80-84 years: 1.49 (1.31-1.71); age $\geq 85$ years: 1.45 (1.22-1.72); black race: 1.25 (1.03-1.53); heart failure: 2.51 (2.04-3.08); diabetes with complications: 1.27 (1.03-1.57); and urban hospital location: 1.35 (1.01-1.80). OR, Odds ratio; $A V R$, aortic valve replacement; $C A B G$, coronary artery bypass grafting; $C I$, confidence interval. 
TABLE E1. Codes from the ICD-9-CM and CCS used to identify procedures and diagnoses

\begin{tabular}{|c|c|c|}
\hline Characteristic & Source & Codes \\
\hline \multicolumn{3}{|l|}{ Procedure-related codes } \\
\hline Aortic valve replacement & ICD-9-CM & $35.21,35.22$ \\
\hline Aortic root replacement & ICD-9-CM & $38.44,38.45$ \\
\hline Mitral valve surgery & ICD-9-CM & $35.12,35.23,35.24$ \\
\hline Pulmonic valve surgery & ICD-9-CM & $35.13,35.25,35.26$ \\
\hline Tricuspid valve surgery & ICD-9-CM & $35.14,35.27,35.28$ \\
\hline Coronary artery bypass grafting & $\mathrm{CCS}$ & 44 \\
\hline Intra-aortic balloon pump & ICD-9-CM & 37.61 \\
\hline Hemodialysis & CCS & 58 \\
\hline \multicolumn{3}{|l|}{ Diagnosis-related codes } \\
\hline Acute myocardial infarction & CCS & 100 \\
\hline Unstable angina & ICD-9-CM & 411.1 \\
\hline Prior myocardial infarction & ICD-9-CM & 412 \\
\hline Family history of coronary artery disease & ICD-9-CM & V17.3 \\
\hline Diabetes without complications & CCS & 49 \\
\hline Diabetes with complications & $\mathrm{CCS}$ & 50 \\
\hline Peripheral artery disease & $\mathrm{CCS}$ & $114,115,116$ \\
\hline Cardiac arrest & $\mathrm{CCS}$ & 107 \\
\hline Congestive heart failure & $\mathrm{CCS}$ & 108 \\
\hline Infective endocarditis & ICD-9-CM & $421.0,421.1,421.9,074.22,098.84,036.42,112.81,115 . \mathrm{X} 4$ \\
\hline Left ventricular dysfunction & ICD-9-CM & $428.1,428.20,428.21,428.22,428.23,428.40,428.41,428.42,428.43$ \\
\hline Cardiogenic shock & ICD-9-CM & 785.51 \\
\hline End-stage renal disease & ICD-9-CM & 585.6 \\
\hline Smoking & ICD-9-CM & V15.82, 305.1 \\
\hline Obesity & ICD-9-CM & $278.00-278.03$ \\
\hline Dyslipidemia & CCS & 53 \\
\hline Prior stroke & ICD-9-CM & V12.54 \\
\hline \multicolumn{3}{|l|}{ Outcome-related codes } \\
\hline Ischemic stroke & ICD-9-CM & $\begin{array}{l}\text { 346.60, } 346.61,346.62,346.63,433.01,433.11,433.21,433.31 \\
\quad 433.81,433.91,434.0,434.00,434.01,434.1,434.10,434.11 \\
\quad 434.9,434.90,434.91,436\end{array}$ \\
\hline Transient ischemic attack & CCS & 112 \\
\hline Intracranial hemorrhage & ICD-9-CM & $431,432.0,432.1,432.9$ \\
\hline Subarachnoid hemorrhage & ICD-9-CM & 430 \\
\hline
\end{tabular}

The Elixhauser comorbidities used in the analysis are: congestive heart failure, valvular disease, pulmonary circulation disorders, peripheral vascular disease, hypertension, paralysis, other neurologic disorders, chronic pulmonary disease, diabetes—uncomplicated, diabetes—complicated, hypothyroidism, renal failure, liver disease, peptic ulcer disease excluding bleeding, autoimmune deficiency syndrome/human immunodeficiency virus, lymphoma, metastatic cancer, solid tumor without metastasis, rheumatoid arthritis/collagen vascular diseases, coagulopathy, obesity, weight loss, fluid and electrolyte disorders, blood-loss anemia, deficiency anemia, alcohol abuse, drug abuse, psychosis, depression. ICD-9-CM, International Classification of Diseases-9 Clinical Modification; CCS, Clinical Classifications Software. 
TABLE E2. Baseline characteristics for patients undergoing isolated aortic valve replacement, stratified by age

\begin{tabular}{|c|c|c|c|c|c|}
\hline \multirow[b]{2}{*}{ Characteristics } & \multicolumn{4}{|c|}{ Age (y) } & \multirow[b]{2}{*}{$P$ value } \\
\hline & $<70$ & 70-79 & $80-84$ & $\geq 85$ & \\
\hline $\mathrm{N}$ & 27,981 & 17,951 & 7764 & 3617 & \\
\hline Age $(y)$, mean $(S D)$ & $55.7(11.9)$ & $74.7(2.8)$ & $81.9(1.3)$ & $87.2(2.2)$ & $<.001$ \\
\hline Gender, female & $9750(34.9)$ & $8492(47.3)$ & $4141(53.3)$ & $1938(53.6)$ & $<.001$ \\
\hline Race & & & & & $<.001$ \\
\hline White & $22,479(80.4)$ & $15,327(85.4)$ & $6797(87.6)$ & $3263(90.2)$ & \\
\hline Black & $1733(6.2)$ & $751(4.2)$ & $263(3.4)$ & $89(2.5)$ & \\
\hline Other & $3762(13.5)$ & $1867(10.4)$ & $703(9.1)$ & $264(7.3)$ & \\
\hline \multicolumn{6}{|l|}{ Comorbidities } \\
\hline Diabetes & $5681(20.3)$ & $4821(26.9)$ & $1717(22.1)$ & $593(16.4)$ & $<.001$ \\
\hline Hypertension & $15,274(55.2)$ & $11,740(66.3)$ & $5037(65.6)$ & $2328(65.0)$ & $<.001$ \\
\hline Smoking & $7630(27.3)$ & 3537 (19.7) & $1127(14.5)$ & $443(12.3)$ & $<.001$ \\
\hline Dyslipidemia & $10,020(35.8)$ & $7981(44.5)$ & $3221(41.5)$ & $1349(37.3)$ & $<.001$ \\
\hline Obesity & $4262(15.4)$ & $2124(12.0)$ & $482(6.3)$ & $120(3.4)$ & $<.001$ \\
\hline Peripheral artery disease & $2926(10.6)$ & 1997 (11.3) & $931(12.1)$ & 425 (11.9) & $<.001$ \\
\hline Chronic pulmonary disease & $5132(18.6)$ & $3989(22.5)$ & $1500(19.5)$ & $622(17.4)$ & $<.001$ \\
\hline Prior stroke & $495(1.8)$ & $470(2.6)$ & $225(2.9)$ & $115(3.2)$ & $<.001$ \\
\hline Prior myocardial infarction & $837(3.0)$ & $851(4.7)$ & 419 (5.4) & $186(5.1)$ & $<.001$ \\
\hline Cardiogenic shock & $488(1.7)$ & $364(2.0)$ & $190(2.5)$ & $94(2.6)$ & $<.001$ \\
\hline Left ventricular dysfunction & $1103(3.9)$ & $805(4.5)$ & $456(5.9)$ & $276(7.6)$ & $<.001$ \\
\hline Number of Elixhauser comorbidities, mean (SD) & $3.0(1.5)$ & $3.4(1.6)$ & $3.5(1.6)$ & $3.4(1.6)$ & $<.001$ \\
\hline \multicolumn{6}{|l|}{ Hospital characteristics } \\
\hline Volume (/y) & & & & & $<.001$ \\
\hline$<50$ & $7290(26.1)$ & $4483(25.0)$ & $1721(22.2)$ & $659(18.2)$ & \\
\hline $50-99$ & $7533(26.9)$ & $4932(27.5)$ & $2082(26.8)$ & 852 (23.6) & \\
\hline $100-199$ & $7968(28.5)$ & $5084(28.3)$ & $2201(28.4)$ & $1056(29.2)$ & \\
\hline$\geq 200$ & $5190(18.6)$ & $3452(19.2)$ & $1760(22.7)$ & $1050(29.0)$ & \\
\hline Location & & & & & .7 \\
\hline Urban & 26,983 (96.9) & $17,309(96.8)$ & 7495 (97.0) & $3504(97.1)$ & \\
\hline Rural & $857(3.1)$ & $573(3.2)$ & $235(3.0)$ & $104(2.9)$ & \\
\hline Teaching status & & & & & $<.001$ \\
\hline Teaching & 18,831 (67.6) & $11,484(64.2)$ & $5130(66.4)$ & $2498(69.2)$ & \\
\hline Nonteaching & $9009(32.4)$ & $6398(35.8)$ & $2600(33.6)$ & $1110(30.8)$ & \\
\hline
\end{tabular}

$S D$, Standard deviation. 
TABLE E3. Baseline characteristics for patients undergoing AVR + CABG, stratified by age

\begin{tabular}{|c|c|c|c|c|c|}
\hline \multirow[b]{2}{*}{ Characteristics } & \multicolumn{4}{|c|}{ Age (y) } & \multirow[b]{2}{*}{$P$ value } \\
\hline & $<\mathbf{7 0}$ & 70-79 & $80-84$ & $\geq \mathbf{8 5}$ & \\
\hline $\mathrm{N}$ & 14,926 & 19,757 & 8964 & 3726 & \\
\hline Age (y), mean (SD) & $61.6(6.8)$ & $74.8(2.8)$ & $81.9(1.3)$ & $87.0(2.1)$ & $<.001$ \\
\hline Gender, female & $3873(26.0)$ & $6558(33.2)$ & $3408(38.0)$ & $1507(40.5)$ & $<.001$ \\
\hline Race & & & & & $<.001$ \\
\hline White & $12,519(83.9)$ & $17,272(87.5)$ & 7992 (89.2) & 3370 (90.5) & \\
\hline Black & $731(4.9)$ & $662(3.4)$ & $222(2.5)$ & $90(2.4)$ & \\
\hline Other & 1667 (11.2) & $1815(9.2)$ & $747(8.3)$ & $265(7.1)$ & \\
\hline \multicolumn{6}{|l|}{ Comorbidities } \\
\hline Diabetes & 4995 (33.5) & $6144(31.1)$ & $2095(23.4)$ & 743 (19.9) & $<.001$ \\
\hline Hypertension & $9264(63.0)$ & $12,627(65.0)$ & $5699(64.6)$ & 2298 (62.6) & $<.001$ \\
\hline Smoking & $4423(29.6)$ & 3824 (19.4) & $1257(14.0)$ & $401(10.8)$ & $<.001$ \\
\hline Dyslipidemia & $7215(48.3)$ & 9199 (46.6) & $3671(41.0)$ & $1353(36.3)$ & $<.001$ \\
\hline Obesity & $2270(15.4)$ & $1916(9.9)$ & $478(5.4)$ & $130(3.5)$ & $<.001$ \\
\hline Peripheral artery disease & $2045(13.9)$ & $2926(15.1)$ & 1194 (13.5) & $461(12.6)$ & $<.001$ \\
\hline Chronic pulmonary disease & $3371(22.9)$ & $4252(21.9)$ & $1629(18.5)$ & $627(17.1)$ & $<.001$ \\
\hline Prior stroke & $262(1.8)$ & $430(2.2)$ & $237(2.6)$ & $102(2.7)$ & $<.001$ \\
\hline Prior myocardial infarction & $1222(8.2)$ & $1457(7.4)$ & $559(6.2)$ & $257(6.9)$ & $<.001$ \\
\hline Cardiogenic shock & $529(3.5)$ & $668(3.4)$ & $337(3.8)$ & $167(4.5)$ & .008 \\
\hline Left ventricular dysfunction & $638(4.3)$ & $865(4.4)$ & $450(5.0)$ & $250(6.7)$ & $<.001$ \\
\hline Number of Elixhauser comorbidities, mean (SD) & $3.4(1.6)$ & $3.5(1.6)$ & $3.4(1.6)$ & $3.5(1.6)$ & .002 \\
\hline \multicolumn{6}{|l|}{ Hospital characteristics } \\
\hline Volume (/y) & & & & & $<.001$ \\
\hline$<50$ & $4146(27.8)$ & $5056(25.6)$ & $2179(24.3)$ & $817(21.9)$ & \\
\hline $50-99$ & $4165(27.9)$ & $5674(28.7)$ & $2561(28.6)$ & $1028(27.6)$ & \\
\hline $100-199$ & $4297(28.8)$ & $5828(29.5)$ & $2624(29.3)$ & $1124(30.2)$ & \\
\hline$\geq 200$ & 2318 (15.5) & 3199 (16.2) & $1600(17.9)$ & 757 (20.3) & \\
\hline Location & & & & & .046 \\
\hline Urban & $14,345(96.6)$ & $18,993(96.5)$ & $8622(96.5)$ & 3620 (97.4) & \\
\hline Rural & $501(3.4)$ & $698(3.5)$ & $309(3.5)$ & 98 (2.6) & \\
\hline Teaching status & & & & & $<.001$ \\
\hline Teaching & $9516(64.1)$ & $12,082(61.4)$ & $5556(62.2)$ & 2431 (65.4) & \\
\hline Nonteaching & $5330(35.9)$ & 7609 (38.6) & $3375(37.8)$ & 1287 (34.6) & \\
\hline
\end{tabular}

$S D$, Standard deviation. 
TABLE E4. Outcomes among patients undergoing isolated aortic valve replacement, stratified by predicted mortality risk

\begin{tabular}{|c|c|c|c|}
\hline Characteristics & $\begin{array}{c}\text { Low mortality } \\
\text { risk }\end{array}$ & $\begin{array}{l}\text { High mortality } \\
\text { risk }\end{array}$ & $\begin{array}{c}P \\
\text { value }\end{array}$ \\
\hline $\mathrm{N}$ & 52,533 & 3846 & \\
\hline \multicolumn{4}{|l|}{ In-hospital deaths } \\
\hline Total cohort & $1468(2.8)$ & $245(6.4)$ & $<.001$ \\
\hline Urban hospitals & $1439(2.8)$ & $239(6.4)$ & $<.001$ \\
\hline Rural hospitals & $29(1.7)$ & $6(7.0)$ & .001 \\
\hline Teaching hospitals & $1002(2.9)$ & $145(6.1)$ & $<.001$ \\
\hline Nonteaching hospitals & $466(2.7)$ & $100(6.9)$ & $<.001$ \\
\hline \multicolumn{4}{|l|}{ Hospital volume (/y) } \\
\hline$<50$ & $357(2.9)$ & $107(6.3)$ & $<.001$ \\
\hline $50-99$ & $422(2.9)$ & $52(7.4)$ & $<.001$ \\
\hline 100-199 & $420(2.8)$ & $57(7.4)$ & $<.001$ \\
\hline$\geq 200 / y$ & $269(2.5)$ & $29(4.4)$ & .004 \\
\hline \multicolumn{4}{|l|}{ Any neurologic event } \\
\hline Total cohort & $957(1.8)$ & $186(4.8)$ & $<.001$ \\
\hline Urban hospitals & $932(1.8)$ & $183(4.9)$ & $<.001$ \\
\hline Rural hospitals & $25(1.5)$ & $3(3.5)$ & .12 \\
\hline Teaching hospitals & $633(1.8)$ & $114(4.8)$ & $<.001$ \\
\hline Nonteaching hospitals & $324(1.9)$ & $72(5.0)$ & $<.001$ \\
\hline \multicolumn{4}{|l|}{ Hospital volume (/y) } \\
\hline$<50$ & $197(1.6)$ & $70(4.1)$ & $<.001$ \\
\hline $50-99$ & $299(2.1)$ & $46(6.6)$ & $<.001$ \\
\hline $100-199$ & $267(1.8)$ & $49(6.3)$ & $<.001$ \\
\hline$\geq 200$ & $194(1.8)$ & $21(3.2)$ & .01 \\
\hline \multicolumn{4}{|l|}{ Ischemic stroke } \\
\hline Total cohort & $777(1.5)$ & $154(4.0)$ & $<.001$ \\
\hline Urban hospitals & $756(1.5)$ & $152(4.0)$ & $<.001$ \\
\hline Rural hospitals & $21(1.3)$ & $2(2.3)$ & .44 \\
\hline Teaching hospitals & $527(1.5)$ & $95(4.0)$ & $<.001$ \\
\hline Nonteaching hospitals & $250(1.4)$ & $59(4.1)$ & $<.001$ \\
\hline \multicolumn{4}{|l|}{ Hospital volume (/y) } \\
\hline$<50$ & $151(1.2)$ & $59(3.5)$ & $<.001$ \\
\hline $50-99$ & 234 (1.6) & $39(5.6)$ & $<.001$ \\
\hline $100-199$ & $226(1.5)$ & $39(5.0)$ & $<.001$ \\
\hline$\geq 200$ & $166(1.6)$ & $17(2.6)$ & .048 \\
\hline
\end{tabular}

High risk is defined as predicted mortality $\geq 8 \%$; low risk is defined as predicted mortality $<8 \%$.
TABLE E5. Outcomes among patients undergoing aortic valve replacement along with coronary artery bypass grafting, stratified by predicted mortality risk

\begin{tabular}{|c|c|c|c|}
\hline Characteristics & $\begin{array}{c}\text { Low mortality } \\
\text { risk }\end{array}$ & $\begin{array}{l}\text { High mortality } \\
\text { risk }\end{array}$ & $\begin{array}{c}P \\
\text { value }\end{array}$ \\
\hline $\mathrm{N}$ & 42,946 & 3491 & \\
\hline \multicolumn{4}{|l|}{ In-hospital death } \\
\hline Total cohort & $2017(4.7)$ & $333(9.6)$ & $<.001$ \\
\hline Urban hospitals & 1944 (4.7) & $321(9.5)$ & $<.001$ \\
\hline Rural hospitals & $73(4.8)$ & $12(13.8)$ & $<.001$ \\
\hline Teaching hospitals & $1255(4.7)$ & $187(9.5)$ & $<.001$ \\
\hline Nonteaching hospitals & $762(4.8)$ & $146(9.6)$ & $<.001$ \\
\hline \multicolumn{4}{|l|}{ Hospital volume (/y) } \\
\hline$<50$ & $530(5.2)$ & $159(9.5)$ & $<.001$ \\
\hline $50-99$ & $588(4.7)$ & 84 (11.9) & $<.001$ \\
\hline $100-199$ & $616(4.8)$ & $56(8.1)$ & $<.001$ \\
\hline$\geq 200$ & $283(3.9)$ & $34(8.3)$ & $<.001$ \\
\hline \multicolumn{4}{|l|}{ Any neurologic event } \\
\hline Total cohort & $1139(2.7)$ & $190(5.4)$ & $<.001$ \\
\hline Urban hospitals & $1113(2.7)$ & $186(5.5)$ & $<.001$ \\
\hline Rural hospitals & $26(1.7)$ & $4(4.6)$ & .053 \\
\hline Teaching hospitals & $734(2.7)$ & $101(5.1)$ & $<.001$ \\
\hline Nonteaching hospitals & 405 (2.6) & $89(5.9)$ & $<.001$ \\
\hline \multicolumn{4}{|l|}{ Hospital volume (/y) } \\
\hline$<50$ & $265(2.6)$ & $80(4.8)$ & $<.001$ \\
\hline $50-99$ & $347(2.8)$ & $50(7.0)$ & $<.001$ \\
\hline $100-199$ & $312(2.4)$ & $39(5.7)$ & $<.001$ \\
\hline$\geq 200$ & $215(2.9)$ & $21(5.1)$ & .012 \\
\hline \multicolumn{4}{|l|}{ Ischemic stroke } \\
\hline Total cohort & $960(2.2)$ & $162(4.6)$ & $<.001$ \\
\hline Urban hospitals & $938(2.3)$ & $159(4.7)$ & $<.001$ \\
\hline Rural hospitals & $22(1.5)$ & $3(3.5)$ & .1 \\
\hline Teaching hospitals & $625(2.3)$ & $88(4.5)$ & $<.001$ \\
\hline Nonteaching hospitals & $335(2.1)$ & 74 (4.9) & $<.001$ \\
\hline \multicolumn{4}{|l|}{ Hospital volume } \\
\hline$<50$ & $220(2.1)$ & $69(4.1)$ & $<.001$ \\
\hline $50-99$ & $296(2.4)$ & $41(5.8)$ & $<.001$ \\
\hline $100-199$ & $261(2.0)$ & $32(4.6)$ & $<.001$ \\
\hline$\geq 200$ & $183(2.5)$ & $20(4.9)$ & .003 \\
\hline
\end{tabular}

High risk is defined as predicted mortality $\geq 8 \%$; low risk is defined as predicted mortality $<8 \%$. 
TABLE E6. Outcomes among patients undergoing isolated AVR, or AVR + CABG, stratified by age, after excluding patients with cardiogenic shock or acute myocardial infarction during the hospitalization

\begin{tabular}{|c|c|c|c|c|c|}
\hline \multirow[b]{2}{*}{ Characteristics } & \multicolumn{4}{|c|}{ Age (y) } & \multirow{2}{*}{$\begin{array}{c}P \\
\text { value } \\
\end{array}$} \\
\hline & $<70$ & 70-79 & $80-84$ & $\geq 85$ & \\
\hline \multicolumn{6}{|l|}{ Isolated AVR } \\
\hline $\mathrm{N}$ & 26,975 & 17,215 & 7386 & 3431 & \\
\hline In-hospital death & $406(1.5)$ & $492(2.9)$ & $298(4.1)$ & $175(5.1)$ & $<.001$ \\
\hline $\begin{array}{l}\text { Any neurological } \\
\text { event }\end{array}$ & $332(1.2)$ & $421(2.5)$ & $219(3.0)$ & $108(3.2)$ & $<.001$ \\
\hline Ischemic stroke & $256(1.0)$ & $353(2.1)$ & $178(2.4)$ & $91(2.7)$ & $<.001$ \\
\hline \multicolumn{6}{|l|}{$\mathrm{AVR}+\mathrm{CABG}$} \\
\hline $\mathrm{N}$ & 13,009 & 17,248 & 7724 & 3132 & \\
\hline In-hospital death & $343(2.6)$ & 629 (3.7) & $359(4.7)$ & $172(5.5)$ & $<.001$ \\
\hline $\begin{array}{l}\text { Any neurologic } \\
\text { event }\end{array}$ & $276(2.1)$ & $476(2.8)$ & $258(3.3)$ & $109(3.5)$ & $<.001$ \\
\hline Ischemic stroke & $242(1.9)$ & $394(2.3)$ & $217(2.8)$ & $92(2.9)$ & $<.001$ \\
\hline
\end{tabular}

TABLE E7. Outcomes among patients undergoing isolated AVR, or AVR + CABG, stratified by predicted mortality risk, after excluding patients with cardiogenic shock or acute myocardial infarction during hospitalization

\begin{tabular}{lccc}
\hline \multicolumn{1}{c}{ Characteristics } & $\begin{array}{c}\text { Low mortality } \\
\text { risk }\end{array}$ & $\begin{array}{c}\text { High mortality } \\
\text { risk }\end{array}$ & $\begin{array}{c}\boldsymbol{P} \\
\text { value }\end{array}$ \\
\hline Isolated AVR & & & \\
$\mathrm{N}$ & 50,546 & 3580 & \\
In-hospital death & $1161(2.31)$ & $191(5.4)$ & $<.001$ \\
Any neurologic event & $892(1.8)$ & $170(4.8)$ & $<.001$ \\
Ischemic stroke & $720(1.4)$ & $140(3.9)$ & $<.001$ \\
AVR + CABG & & & \\
$\mathrm{N}$ & 37,500 & 2820 & \\
In-hospital death & $1280(3.4)$ & $196(7.0)$ & $<.001$ \\
Any neurologic event & $952(2.5)$ & $144(5.1)$ & $<.001$ \\
Ischemic stroke & $799(2.1)$ & $125(4.4)$ & $<.001$ \\
\hline High risk is defined as predicted mortality $\geq 8 \% ;$ low risk is defined as predicted \\
mortality $<8 \%$. AVR, Aortic valve replacement; CABG, coronary artery bypass \\
grafting.
\end{tabular}

